\title{
Comparative Histopathology of Biomphalaria glabrata, $B$. tenagophila and $B$. straminea with Variable Degrees of Resistance to Schistosoma mansoni Miracidia
}

\author{
Cecilia Pereira de Souza, Claudia Cunha Borges/ ${ }^{+}$, Andréa Guimarães \\ Santana*, Zilton A Andrade* $/++$
}

Laboratório de Malacologia, Centro de Pesquisas René Rachou-FIOCRUZ, Av. Augusto de Lima 1715, 30190002 Belo Horizonte, MG, Brasil *Laboratório de Patologia Experimental, Centro de Pesquisas Gonçalo MonizFIOCRUZ, Rua Valdemar Falcão 121, 40295-001 Salvador, BA, Brasil

A comparative histopathological study of three snails species - Biomphalaria glabrata, B. tenagophila and B. straminea - which had been infected with Schistosoma mansoni miracidia revealed similar qualitative features, consisting of areas of sporocyst proliferation and differentiation associated with reactive host reaction, at the time they were actively eliminating great number of cercariae. However, in specimens that were exposed to miracidia but failed to eliminate cercariae later on, different histopathological pictures were observed in different snail species.

While B. glabrata exhibited frequent focal (granulomatous) proliferation of amebocytes in several organs, B. tenagophila and B. straminea only rarely showed such reactive changes, suggesting that the mechanism of resistance to miracidial infection probably follows different pathways in the snail species studied.

Key words: Biomphalaria histopathology - Schistosoma mansoni - differential susceptibility

Biomphalaria glabrata is highly susceptible to infection with Schistosoma mansoni miracidia and represents the main intermediate host for that trematode in the large endemic area of northeastern and southeastern Brazil (Paraense 1970). However, susceptibility to infection is variable among different specimens, a high degree of resistance being sometimes exhibited by some of them (Pan 1965). Recently, Godoy et al. (1997) reported that B. glabrata, which completely failed to emit cercariae after a relatively prolonged time following exposition to $S$. mansoni miracidia, exhibited focal inflammatory and granulomatous lesions in several organs in the absence of demonstrable parasites, histopathologically.

Such lesions were interpreted as the aftermath of a successful clearance reaction against invading sporocysts, suggestive of high degree of resistance.

There are two other important $S$. mansoni intermediate host snails in Brazil: B. tenagophila and B. straminea. Several studies have attempted to comparatively evaluate the behavior of those susceptible snails regarding their interaction with $S$.

\footnotetext{
${ }^{+}$CNPq Research Fellow

++ Corresponding author. Fax: +55-71-356.4292

Received 19 February 1997

Accepted 12 May 1997
}

mansoni (Barbosa 1975, Paraense \& Correa 1978, Souza et al. 1995a, b) but whether the peculiar tissue reactivity described by Godoy et al. (1997) in resistant $B$. glabrata does ever occur in these other two species, and to which extent and frequency, has hitherto not been reported.

Present investigation is concerned with a comparative study of the tissue reactions in three $S$. mansoni intermediate hosts: $B$. glabrata, $B$. tenagophila and B. straminea. The purpose is to comparatively describe the histopathologic findings and attempt to correlate them with previous malacological data indicative of different degrees of susceptibility among the three snail species.

\section{MATERIALS AND METHODS}

Laboratory bred B. glabrata, B. tenagophila and $B$. straminea from the State of Minas Gerais, Brazil, were individually exposed to 50 miracidia of $S$. mansoni. The strain used was the SJ-strain which is better adapted to B. tenagophila snails (Paraense \& Correa 1981). The exposed snails were divided into two groups according to whether they were or not emitting cercariae. Emission of cercariae occurred after the first month from exposure. Those snails that did not emit cercariae were observed during three months and were then selected for study. Randomly chosen snails, representative of the two groups and belonging to the three species were submitted to histological exami- 
nation. Since $B$. glabrata presented high mortality rate, the cases for histological study was complemented with previously obtained material. As controls, non-exposed snails belonging to the same three species were also used. The snails were removed from the shell under menthol anesthesia, fixed in totum in Bouin's fluid for $6 \mathrm{hr}$ and then transferred to $70 \%$ alcohol. Further procedures included dehydration in $100 \%$ alcohol, clearing in xylol and paraffin embedding. Five $\mu \mathrm{m}$ paraffinembedded sections were stained with hematoxylin and eosin, and eventually with the sirius-red method for collagen and the Periodic-acid Schiff (PAS) with and without previous diastase treatment. Slides stained with sirius-red were also microscopically examined under polarized light.

\section{RESULTS}

Table I shows the general comparative malacological results obtained with the infection of the three snail species. B. glabrata was the most susceptible, followed by B. tenagophila and $B$. straminea in that order. Table II summarizes the main histological results. Quantitative histological findings were different for each snail species. Description will consider the qualitative changes which were common to all snails belonging to each group, according to cercarial elimination.
Snails shedding cercariae - Developing sporocysts were found in large numbers in all snails which were eliminating cercariae, but not in those that did not. The secondary sporocysts found appeared larger and more numerous in B. glabrata, and slightly more frequent in $B$. tenagophila than in $B$. straminea, but the general microscopical appearance was similar regardless snail species. Sporocysts were usually formed as a space-occupying lesion, without any visible changes in the neighboring snail tissues. However, sporocysts were also found in several locations, side by side with variable degree of tissue reactions (Fig. 1). These latter consisted of either focal and diffuse proliferation of amebocytes, frequently forming encapsulating or granulomatous structures centered by sporocyst and cercaria remnants, and limited peripherally by concentric laminations of thin fibers.

Sometimes an encapsulating, ring-like, cellular reaction was formed around a collection of viable cercariae, which exhibited different degrees of maturation (Fig. 2). Cells involved in these reactions were mainly macrophage-like amebocytes. They varied in shape from round to fusiform, with little variation in size. The stroma of the inflammatory foci was represented by an increased amount of the amorphous and fibrillar components of the extracellular matrix, sometimes mimicking the pro-

TABLE I

Comparative results on the infection of three Biomphalaria species by 50 miracidia of Schistosoma mansoni

\begin{tabular}{lcccc}
\hline Species & $\begin{array}{c}\text { Exposed } \\
\text { snails }\end{array}$ & No. of positives & Infection \\
rate $^{a}$ & Mortality $_{\text {rate }^{a}}$ \\
\hline B. glabrata & 50 & 26 & $96.3 \%$ & $46 \%$ \\
B. tenagophila & 50 & 17 & $68 \%$ & $50 \%$ \\
B. straminea & 50 & 6 & $18.7 \%$ & $36 \%$ \\
\hline
\end{tabular}

a: 37 days after exposition

TABLE II

Comparative histopathological study of Biomphalaria glabrata, B. tenagophila and B. straminea exposed to Schistosoma mansoni miracidia, emitting (Positives) or not cercariae (Negatives) after three months from exposure, regarding the presence of sporocysts (Sp.) and inflammatory lesions (L.)

\begin{tabular}{|c|c|c|c|c|c|c|c|c|c|c|c|c|}
\hline \multirow{4}{*}{ Organs } & & \multicolumn{11}{|c|}{ Snail species } \\
\hline & \multicolumn{4}{|c|}{ B. glabrata } & \multicolumn{4}{|c|}{ B. tenagophila } & \multicolumn{4}{|c|}{ B. straminea } \\
\hline & \multicolumn{2}{|c|}{ Positive } & \multicolumn{2}{|c|}{ Negative } & \multicolumn{2}{|c|}{ Positive } & \multicolumn{2}{|c|}{ Negative } & \multicolumn{2}{|c|}{ Positive } & \multicolumn{2}{|c|}{ Negative } \\
\hline & Sp. & $\mathrm{L}$. & Sp. & L. & Sp. & L. & Sp. & L. & Sp. & L. & Sp. & L. \\
\hline Kidney & +++ & ++ & - & ++ & + & ++ & - & + & + & + & - & - \\
\hline Dig. Gl. & + & ++ & - & + & ++ & ++ & - & - & ++ & ++ & - & - \\
\hline Ovotestis & +++ & + & - & ++ & ++ & +++ & - & + & +++ & ++ & - & + \\
\hline Album. Gl. & ++ & + & - & +++ & ++ & + & - & - & - & - & - & - \\
\hline Others & ++ & ++ & - & + & - & - & - & - & - & - & - & - \\
\hline
\end{tabular}

+: few (sporocyasts and/or lesions); ++: moderate; +++: intense; -: absence 


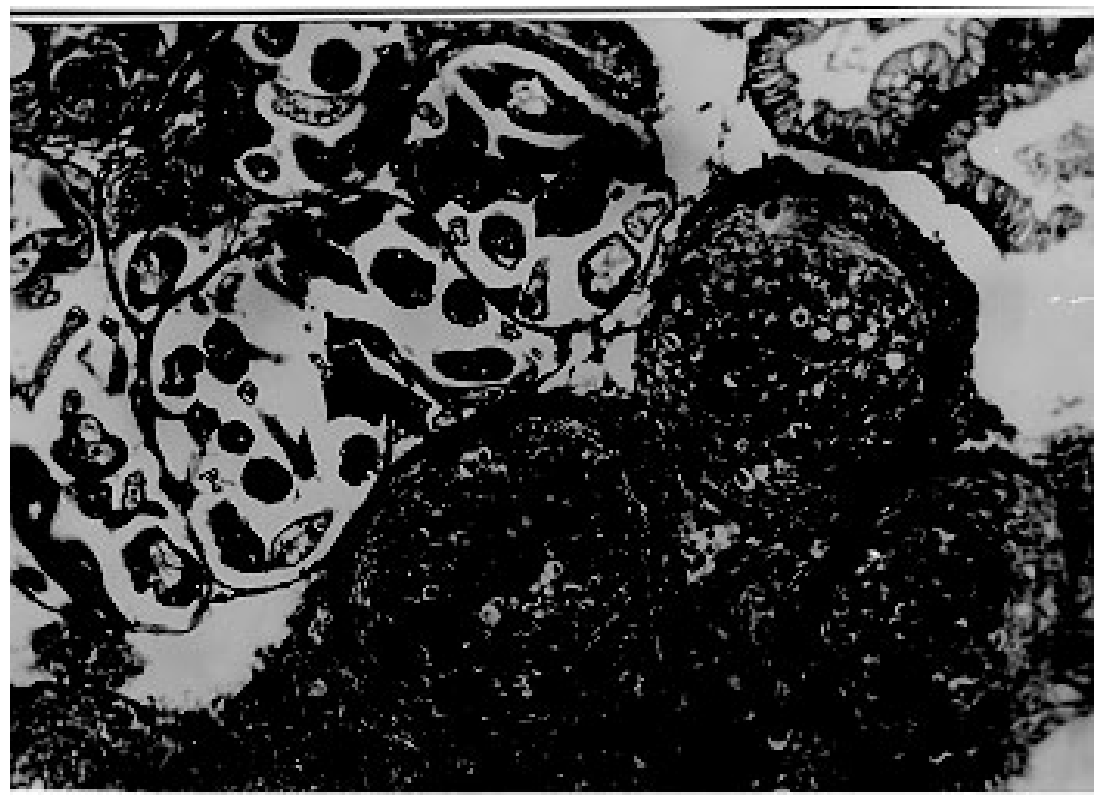

Fig. 1: aspect of Biomphalaria glabrata digestive glands showing both parasites and tissue reaction. Parasites are seen above left, with sporocysts and cercariae at several stages of development. At lower right there is dense amebocyte proliferation forming three nodular (granulomatous) reactions. Structures of the digestive glands can be seen at upper right. Hematoxylin \& eosin, 200X.

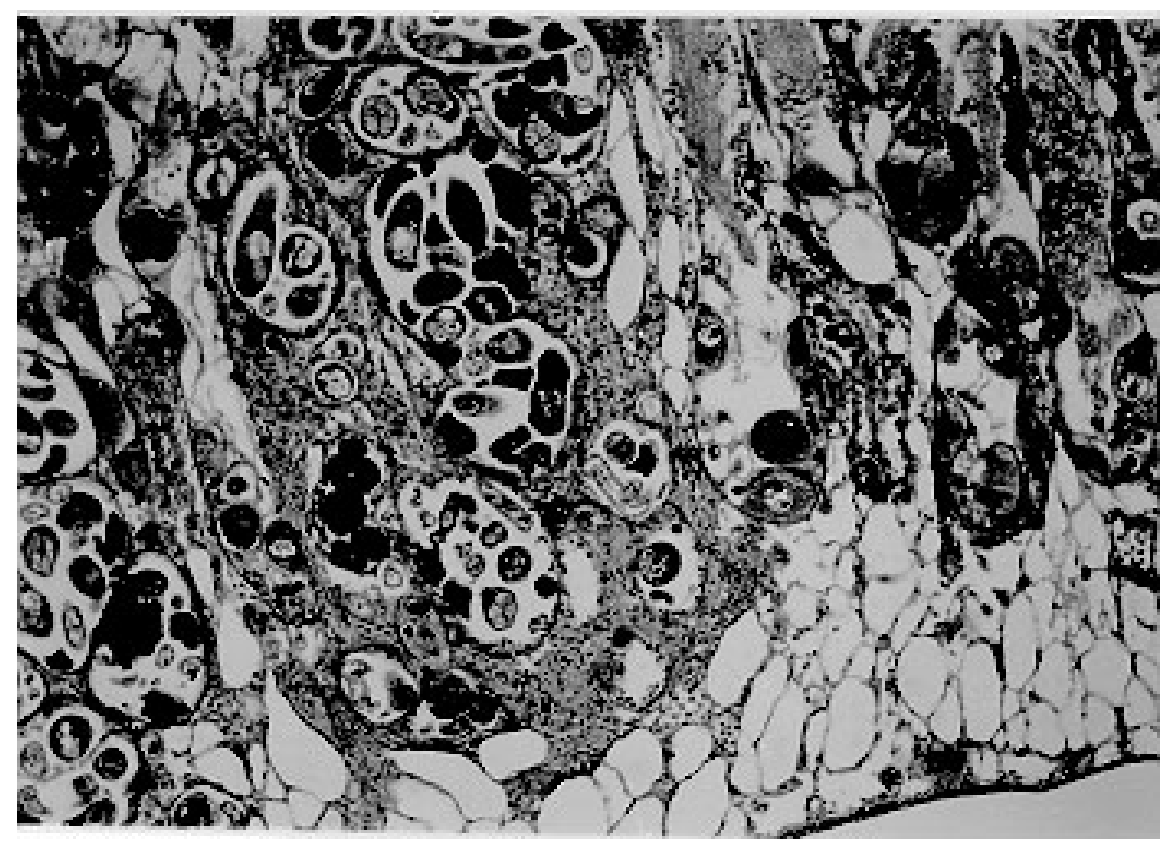

Fig. 2: region of the ovotestis of Biomphalaria straminea showing foci of proliferation of Schistosoma mansoni sporocysts and differentiation of cercariae encircled by a strong stromal reaction, represented by diffuse amebocyte infiltration and thickening of the extracellular matrix. Hematoxylin \& eosin, 150X.

cess of fibrosis seen in vertebrates. However, the newly formed "fibrous" tissue, both within and at the periphery of the inflammatory lesions, did not stain with sirius-red as does vertebrate collagen. In a few instances it did stain, but without the charac- teristic polarization-light refringence. It should be mentioned here that some normal fibers of the extracellular matrix of the snail (especially in the foot) do stain like vertebrate collagen and exhibit birefringence under polarized light. 
Exposed snails that failed to eliminate cercariae - No viable sporocysts were found in histological sections taken from any of the three snail species. However, focal inflammatory tissue reactions were found in several organs in B. glabrata and only rarely in the two other species. In the ovotestis and renal tubular region in the case of B. tenagophila (Fig. 3) and only once, in the region of an atrophic ovo-testis of $B$. straminea (Fig. 4). These reactions were entirely similar to those seen in snails shed-

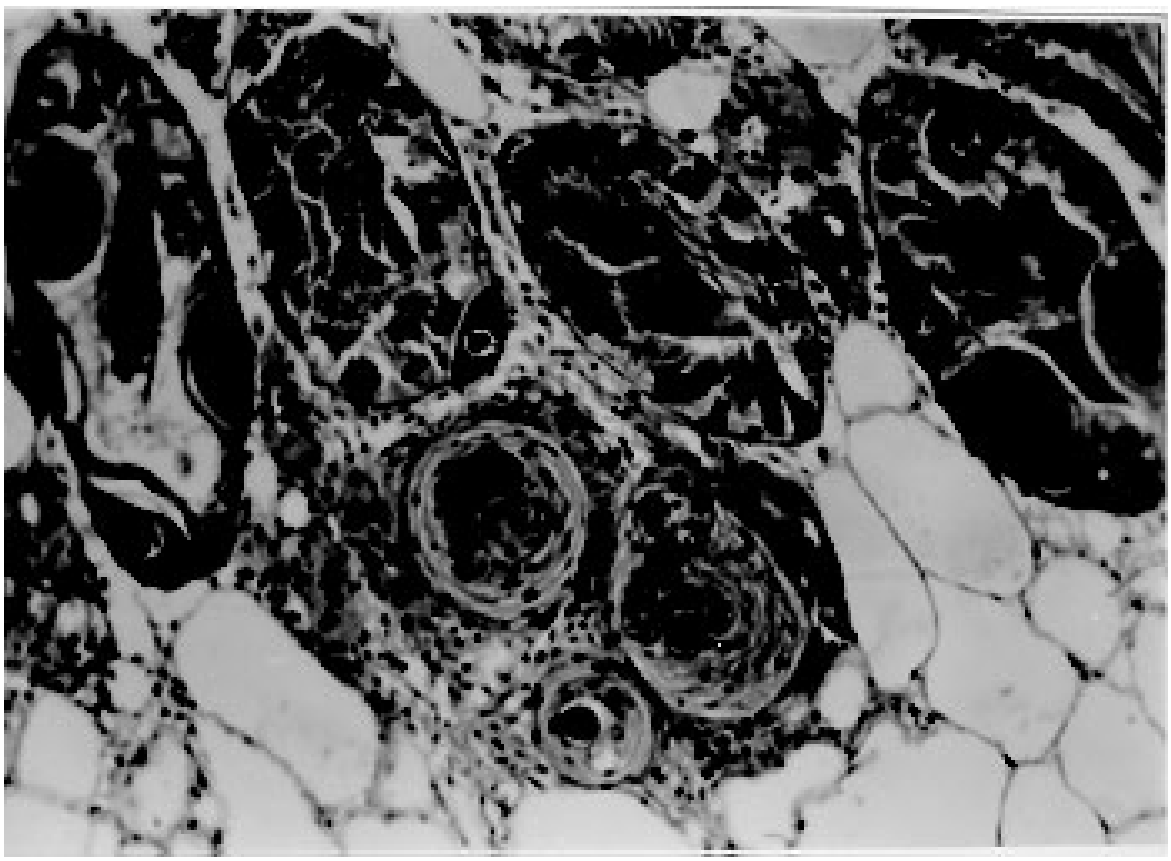

Fig. 3: region of the ovotestis of Biomphalaria straminea which had been infected, but did not eliminate cercariae. It shows infiltration and proliferation of amebocytes and the formation of three nodular lesions, some of them containing dark irregular nonidentified material. The possibility of this latter being sporocyst remnants has not been excluded. Hematoxylin \& eosiin, $200 \mathrm{X}$.

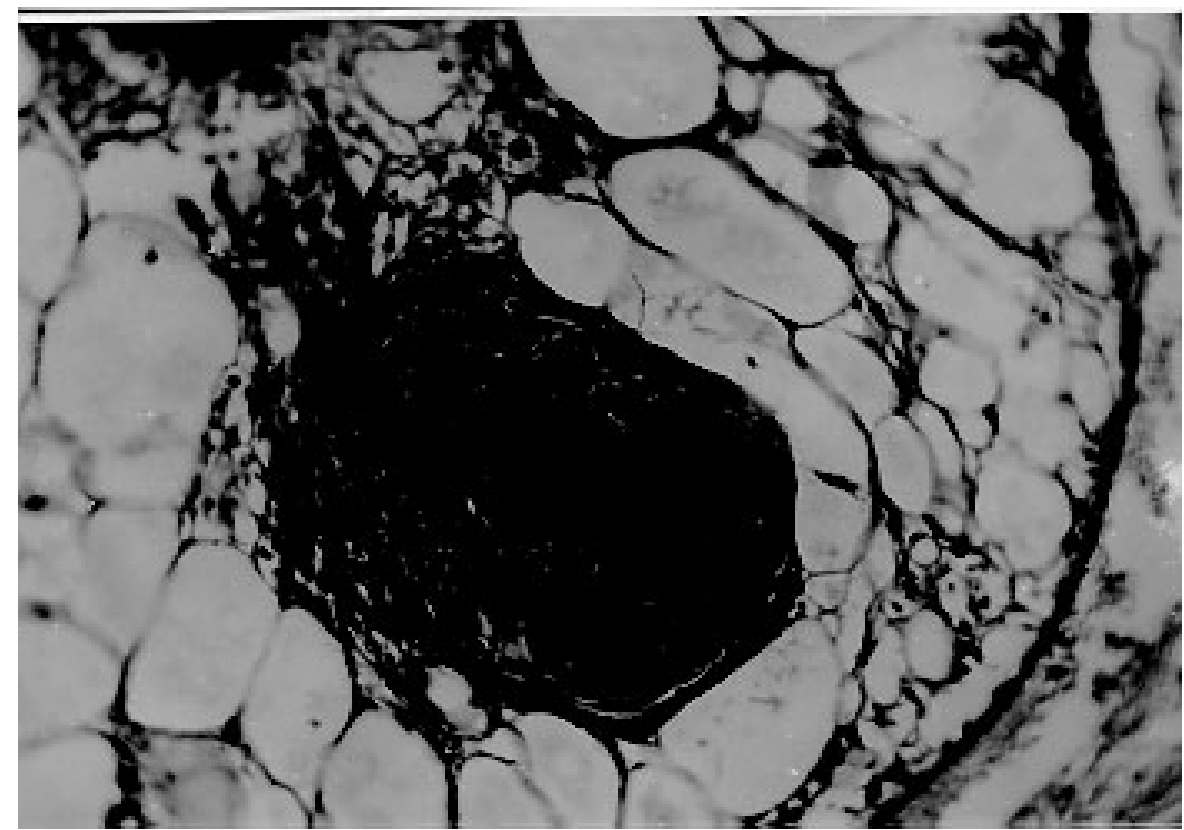

Fig. 4: focal, nodular and dense sporocyst infiltration observed in region of the ovotestis of Biomphalaria tenagophila that did not eliminate cercariae although being exposed to Schistosoma mansoni miracidia 32 days previously. Again, presence of a dark structureless inclusion (arrow) surrounded by reactive cells. Hematoxylin \& eosin, 400X. 
ding many cercariae, and which were found encircling or in close vicinity of proliferating sporocysts. However, no evident sporocystic structures were identified in any of the foci or in any other part of the snail tissues.

Normal non-infected snails - They showed essentially normal histology. No focal or diffuse inflammatory reaction was ever observed.

\section{DISCUSSION}

A tentative histological grading of susceptibility for the three snail species was attempted by considering sporocyst distribution in different organs, their size and number, as well as the tissue reaction elicited by them. In the present investigation this would place B. glabrata, B. tenagophila and $B$. straminea, in that order, as the most susceptible $S$. mansoni intermediate hosts. These results are in keeping with previous ones obtained by a combination of malacological techniques (Souza et al. 1995b).

Susceptible snails give rise to variable numbers of cercariae. Those which are very susceptible can shed numerous cercariae, with no overt reactions, their tissues appearing tolerant to the presence of the multiplying and growing sporocysts (Newton 1952). Others may eliminate only a few cercariae and in them variable degrees of tissue reactions take place (Pan 1965). These reactions usually consist of massive proliferation of amebocytes, with encapsulation and destruction of sporocysts, the cells probably acting in concert with soluble factors in the molluscan hemolymph (Bayne et al. 1980). Recently, some specimens taken from a resistant $\mathrm{F} 15$ generation of $B$. glabrata completely failed to emit cercariae several months after being exposed to numerous miracidia. When they were histologically examined, no sporocysts were found, but focal and diffuse inflammatory reactions, similar to those seen in infected and resistant snails, appeared at several locations. Such peculiar reactions were not found in normal, nonexposed control snails. They were thought to represent cicatrices left by destroyed sporocysts (Godoy et al. 1997). This kind of delayed-developed resistance probably represents an alternative and novel kind of host defense mechanism against S. mansoni miracidia, in spite of evidences suggesting that $S$. mansoni sporocysts can sometimes better develop their ability to interfere with the defense mechanism of the snail as they grow older (Lie et al. 1980). Thus, the amebocytic reaction that is already known to be partially inhibitory of sporocyst development, appears sometimes to be totally effective.

Therefore, protection against miracidial invasion could be provided by at least two mechanisms.
One being represented by the already known example of direct miracidium destruction which occurs soon after penetration. Locker et al. (1986) found miracidium-amebocyte contact within $3 \mathrm{hr}$ and phagocytosis of sporocysts microvilli and pieces of tegument within $7.5 \mathrm{hr}$, while extensive pathology was demonstrated within $24 \mathrm{hr}$ and by $48 \mathrm{hr}$ only scattered remnants of sporocysts remained. The other mechanism would be represented by the one here postulated, that is, a successful mounting of a destructive reaction when several sporocysts have already disseminated throughout the snail tissues.

This second mechanism appeared frequently and widespread in B. glabrata, but it was only rarely seen in the other two species. Strongly resistant B. tenagophila and B. straminea rather utilize the second mechanism, the killing of invading miracidia probably occurring soon after their penetration into the snail tegument, which would leave no residual changes.

\section{REFERENCES}

Barbosa FS 1975. Survival and cercaria production of Brazilian Biomphalaria glabrata and B. straminea infected with Schistosoma mansoni. J Parasitol 61: 151-152.

Bayne CJ, Buckley PM, Dewan PC 1980. Macrophagelike hemocytes of resistant Biomphalaria glabrata are cytotoxic for sporocysts of Schistosoma mansoni in vitro. J Parasitol 66: 413-419.

Godoy A, Souza CP, Guimarães CT, Andrade ZA 1997. Unusual histological findings in Biomphalaria glabrata with high degree of resistance to Schistosoma mansoni miracidia. Mem Inst Oswaldo Cruz, 92: 121-122.

Lie KJ, Jeong KH, Heyneman D 1980. Tissue reaction induced by Schistosoma mansoni in Biomphalaria glabrata. Ann Trop Med Parasitol 78: 157-166.

Loker ES, Bayne CJ, Yui MA 1986. Echinostoma paraensei: hemocytes of Biomphalaria glabrata as targets of Echinostoma mediate interference with host snails resistance to Schistosoma mansoni. Exper Parasitol 62: 149-154.

Newton WL 1952. The comparative tissue reaction of two strains of Australorbis glabratus to infection with Schistosoma mansoni. J Parasitol 38: 362366.

Pan C-T 1965. Studies on the host-parasite relationship between Schistosoma mansoni and the snail Australorbis glabratus. Am J Trop Med Hyg 14: 931-975.

Paraense WL 1970. Planorbídeos hospedeiros intermediários do Schistosoma mansoni, p. 13-20. In AS Cunha, Esquistossomose mansoni. Sarvier \& USP, São Paulo.

Paraense WL, Correa LR 1978. Differential susceptibility of Biomphalaria tenagophila populations to infection with a strain of Schistosoma mansoni. J Parasitol 64: 822-826. 
Paraense WL, Correa LR 1981. Observations of two biological races of Schistosoma mansoni. Mem Inst Oswaldo Cruz 76: 287-291.

Souza CP, Janotti-Passos LK, Freitas JR 1995a. Degree of host-parasite compatibility between Schistosoma mansoni and their intermediate molluscan hosts in
Brazil. Mem Inst Oswaldo Cruz 90: 5-10.

Souza CP, Cunha RCP, Andrade ZA 1995b. Development of Schistosoma mansoni in Biomphalaria tenagophila, Biomphalaria straminea and Biomphalaria glabrata. Rev Inst Med Trop São Paulo 37: 201-206. 